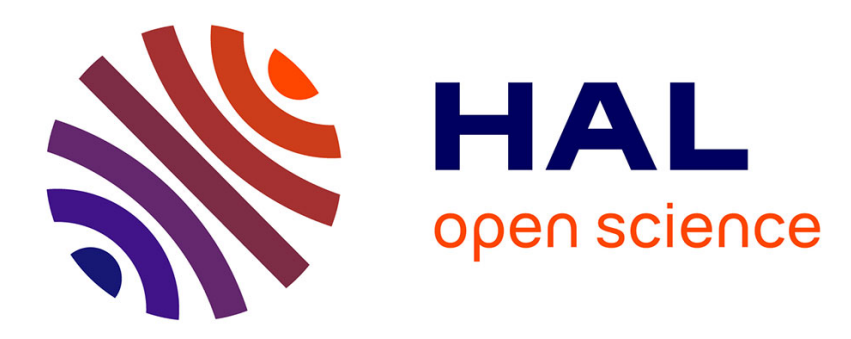

\title{
Some application of synchrotron radiation
}

H. Fuess

\section{- To cite this version:}

H. Fuess. Some application of synchrotron radiation. Journal de Physique IV Proceedings, 1993, 03 (C7), pp.C7-2129-C7-2136. 10.1051/jp4:19937338 . jpa-00251985

\section{HAL Id: jpa-00251985 https://hal.science/jpa-00251985}

Submitted on 1 Jan 1993

HAL is a multi-disciplinary open access archive for the deposit and dissemination of scientific research documents, whether they are published or not. The documents may come from teaching and research institutions in France or abroad, or from public or private research centers.
L'archive ouverte pluridisciplinaire HAL, est destinée au dépôt et à la diffusion de documents scientifiques de niveau recherche, publiés ou non, émanant des établissements d'enseignement et de recherche français ou étrangers, des laboratoires publics ou privés. 


\title{
Some application of synchrotron radiation
}

\author{
H. FUESS
}

Technische Hochschule Darmstadt, Strukturforschung, Petersenstrasse 20, 64287 Darmstadt, Germany

\begin{abstract}
Continuous tuneable wavelength in the range $0.01 \AA<\lambda<100 \AA$, high brilliance and parallelity of the beam are the outstanding properties for all applications of synchrotron radiation in condensed matter research. High angular and time resolution in synchrotron $\mathrm{X}$-ray diffraction may be achieved. Powder Diffraction pattern with a full width at half maximum (FWHM) of Bragg reflections of $\Delta \theta-0.02$ display a resolution about five times better than laboratory equipment. Thus the investigation of structural phase transitions with only minor metric changes are feasible as well as direct determination of crystal structures from powder data. Registration of complete powder patterns in a few milliseconds opens the road to kinetic studies of crystallisation from glasses or melt and to structural phase transitions. The information from diffraction experiments which provide information on long range order is related to X-ray absorption experiments (XANES and EXAFS).

$x$-ray absorption will provide information on the local environment of atoms (EXAFS) or on its electronic nature.

Texture, strain and stress investigations with synchrotron radiation offer advantages as compared to laboratory $X-r a y$ work. The angular resolution is considerably improved due to the parallel beam geometry and the small beam size and the penetration depth may be varied by a factor of 6 . Thus not only general orientation distribution functions but the anisotropy strain and complex stress behaviour at surfaces may be investigated in particular grains. Furthermore all kinds of surface studies at grazing incidence are performed with considerable advantage.
\end{abstract}




\section{1. synchrotron radiation}

Radiation from synchrotron sources for condensed matter research is now available in many laboratories. The main properties are high brilliance, small divergence of the incoming beam, polarisation (linear in plane of the accelerator ring, elliptical above and below) and a continuous wavelength distribution which allows a tunable incoming energy. Some basic properties of SR compared with a laboratory $X$-ray tube are presented in Table 1. They are assembled in Fig. 1 in a schematic view in a picture presenting a synchrotron ring.

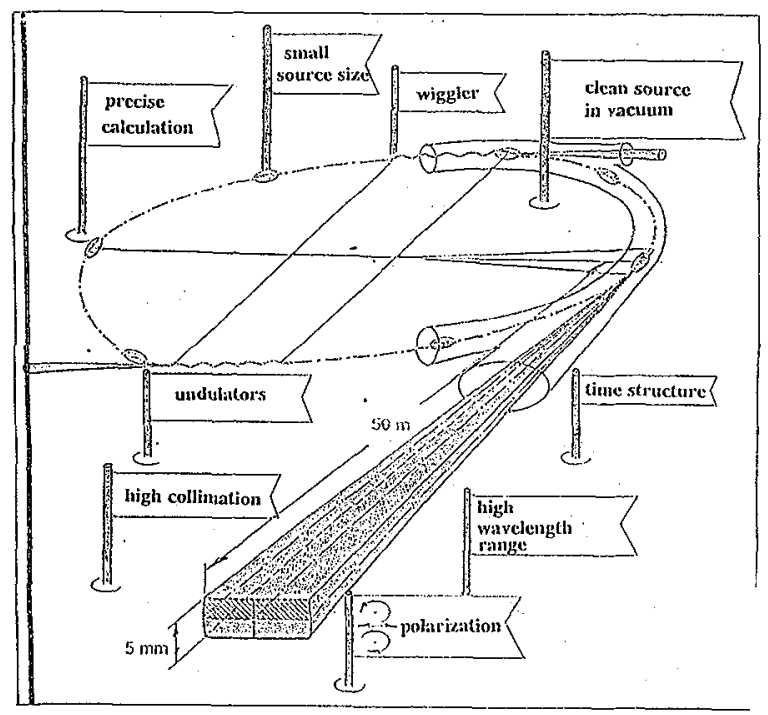

Fig. 1 Schematic presentation of the properties of synchrotron radiation.

Table 1 Properties of $X$-rays (Tube and SR)

Tube

spectrum

angle

source
intensity
$\left[\mathrm{Ph} \mathrm{sec}-1 \mathrm{eV}^{-1} \mathrm{mrad}^{-1}\right.$ ]

polarization

time

continuous

structure charact.

divergent

$\approx 15^{\circ}$

$0.04 \times 8 \mathrm{~mm}^{2}$

$10^{9}$

unpolar.
SR

continuous

parallel

$<0.2 \mathrm{mrad}$

$2 \times 2 \mathrm{~mm}^{2}$

$\geq 10^{13}$

Iinear 90-100\%

in plane

elliptic out of plane

nsec (bunch length)

psec (time intervall) 


\section{Powder diffraction}

The specific properties offer definite advantages to powder diffraction. Fig. 2 presents the installation at beam line B2 at the HASYLAB laboratory at DESY Hamburg [1]. The instrument consists of a blocked double circle $\omega_{1 / \theta}$ plus another single circle $\Omega 2$ aligned along a common axis. Space between these units can accomodate cryostats, furnaces or an Eulerian cradle.

In addition to powder diffraction the instrument is therefore used for the measurement of pole figures, of stress and strain (e.g. [2]).
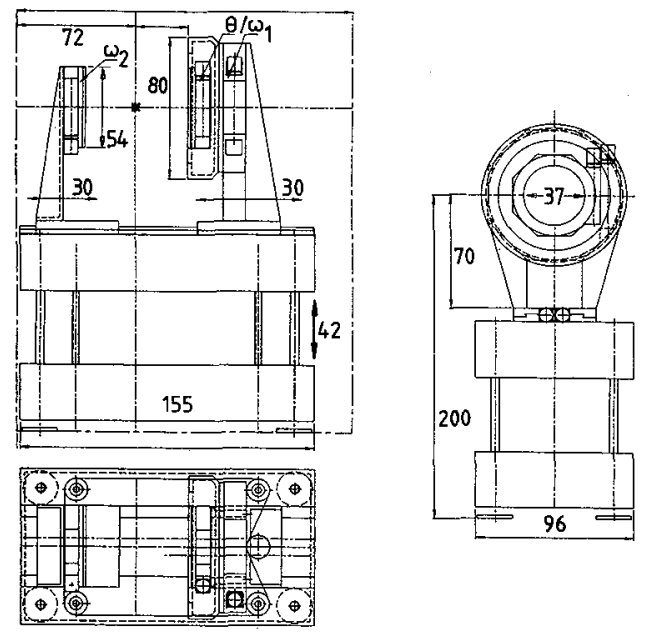

Fig. 2 side-on, end-on, and top view of the instrument. The single circle is on the left, the blocked double-circle unit on the right. The asterisk (*) marks the beam position.

The principle modes of operation are (i) the parallel beam geometry with an $\mathrm{Si}(111)$ crystal analyser and (ii) soller slit between sample and detector or (iii) the Debye-Scherrer geometry with a position sensitive detector (PSD).

A double crystal monochromator and a synthetic multilayer can be used as monochromators. Typical flux rates of about $2 * 10^{8}$ photons per second at a wavelength of $1.26 \AA$ with the double monochromator and of about $1.5 * 10^{10}$ photons with the multilayer are achieved. The optical elements of the beamline are shown in Fig. 3. As an alternative to the standard double crystal monochromator a synthetic multilayer consisting of 200 $\mathrm{si} / \mathrm{W}$ doublelayers of $2.05 \mathrm{~mm}$ thickness each can be installed (Fig. 3b). 
Scintiliation detector

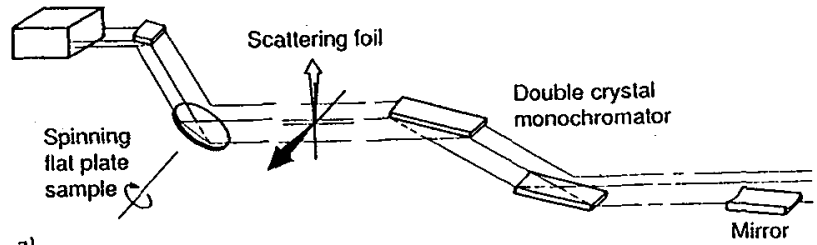

a)
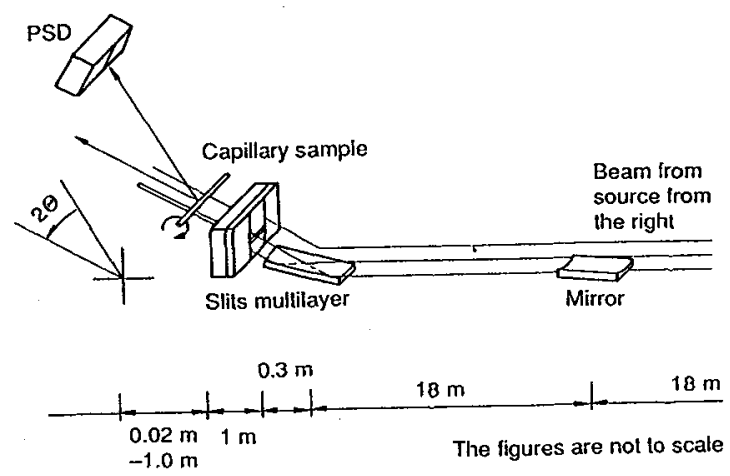

Fig. 3. The two types of monochromators and ther arrangement in the bcamline. a) Double crystal monochromator and scattering foil to monitor intensity and polariza(ion, b) Multilayer monochromator.

\subsection{High angular resolution}

In parallel beam geometry FWHM (full width at half maximum) between $0.01-0.02{ }^{\circ}$ in 20 are obtained at the minimum of resolution. Fig. 4 displays some resolution functions. The quality of the powder data are demonstrated by the powder pattern of $\mathrm{BaCuO}_{2+x}$ (Fig. 5). Diffuse intensity (marked by arrows) is found between the sharp Bragg peaks. This diffuse intensity is due to the excess oxygen which is disordered in that structure.

The parallel beam geometry offers the advantage to analyse real structure in crystals. An example is presented in Fig. 6 which displays the reflection pattern of a thin film of $\mathrm{YBa}_{2} \mathrm{Cu}_{3} \mathrm{O}_{7}$ on a substrate of $\mathrm{SrTiO}_{3}$. Four individual reflections are observed which indicate that the layer prepared by CVD-techniques is not a single crystal layer.

The attribution of the lines was derived from the analysis of the reciprocal lattice [5].

A closely related example is the phase transition of $\mathrm{YBa}_{2}$

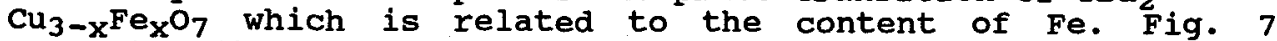
presents the powder pattern in the region of the 400 reflection. The phase transition occurs at about $2.5 \%$ Fe but the high resolution despicts a continuous transition where both, the orthorhombic and the tetragonal phases, are present in the intermediate region [3]. This observation may be correlated to the observation of exsolution lamellae and tweed structures in the electron microscope [4]. 

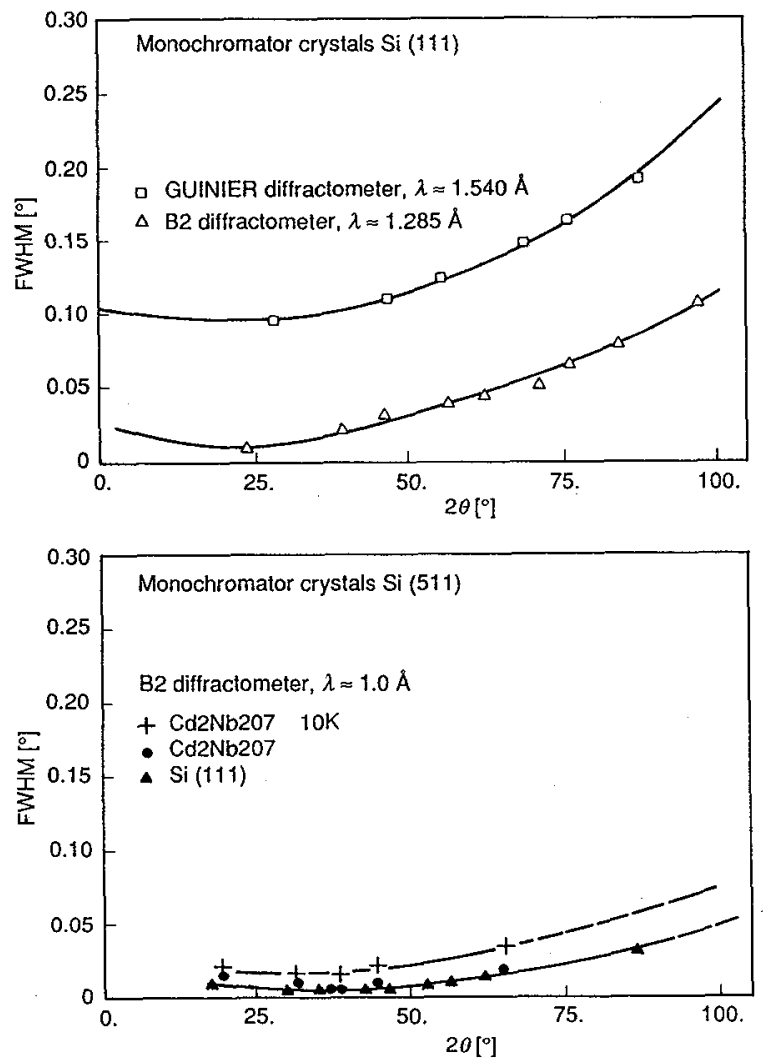

Fig. 4 Resolution functions at the B2 powder diffractometer in highresolution mode with different monochromator crystal arrangements.

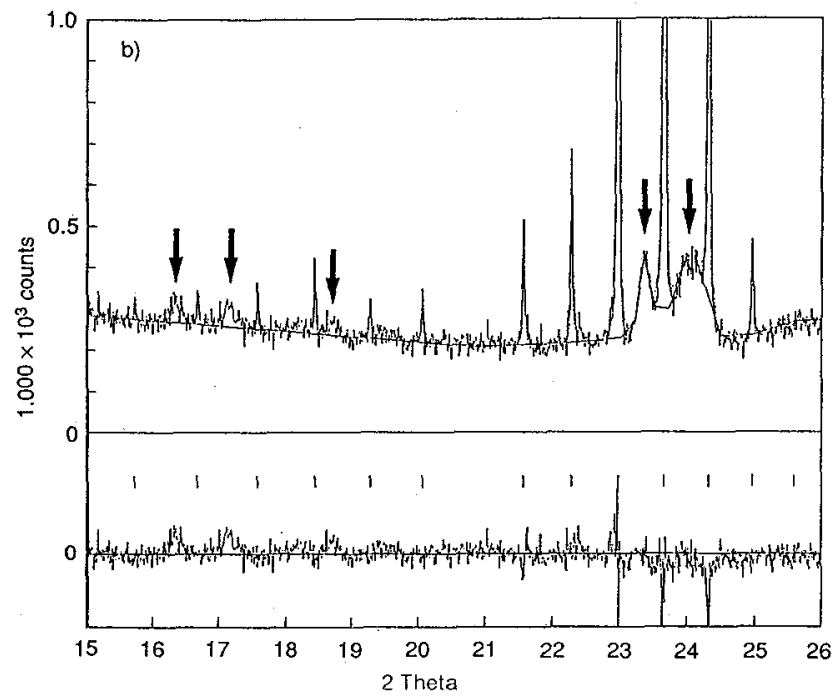

Fig. 5 Rietveld fitted SR powder pattern of $\mathrm{BaCuO}_{2+\mathrm{x}}$ with diffuse reflection not detected with conventioneal equipment 


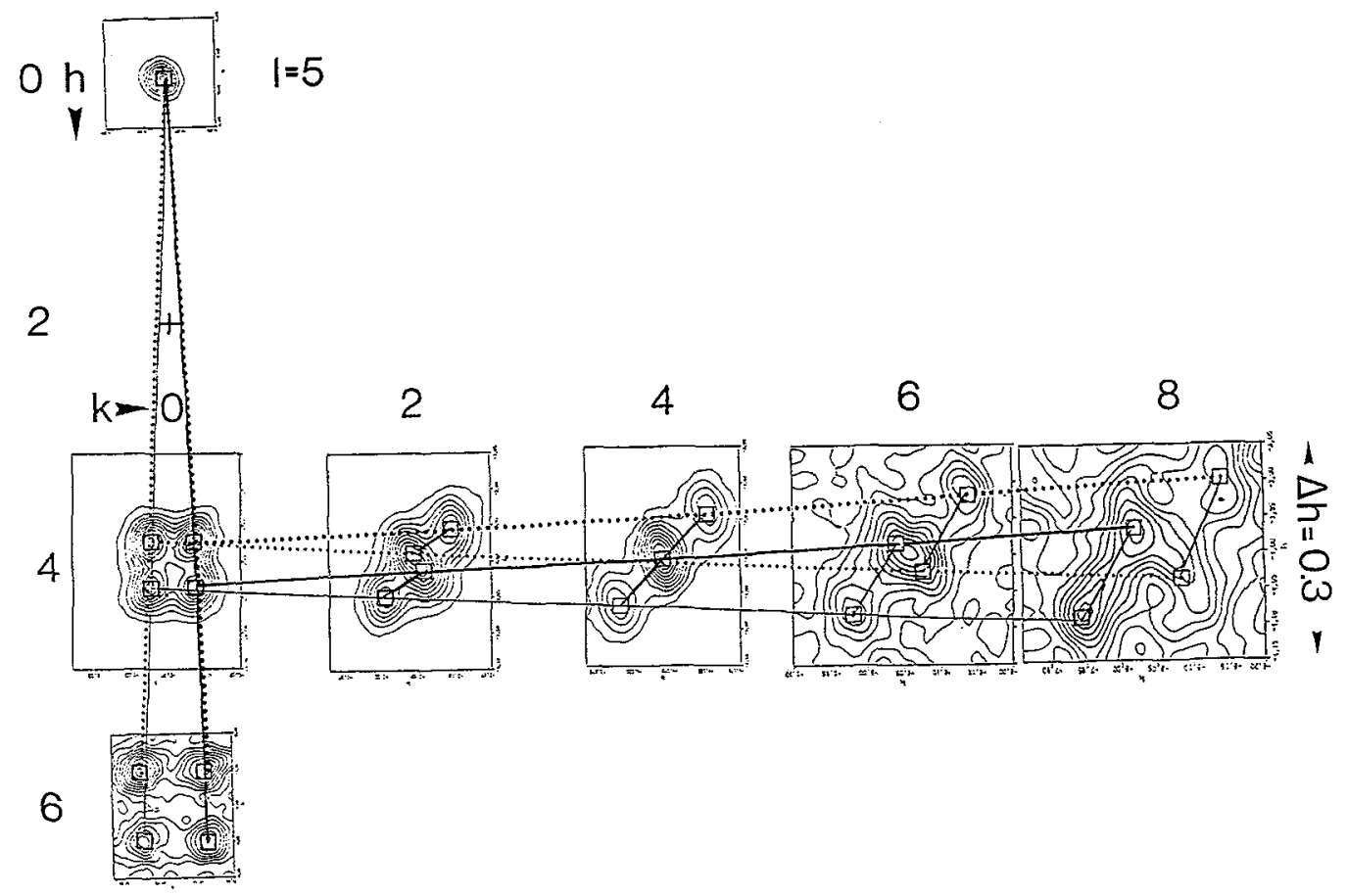

Fig. $6 \mathrm{Ni}$-doped $\mathrm{YBa}_{2} \mathrm{Cu}_{3} \mathrm{O}_{7}(\mathrm{~b} / \mathrm{a}=1.015)$ on $\mathrm{SrTiO}_{3}$ substrate. Shape of some reflections in the layer $1=5$ enlarged by a factor 5.9 with respect to the $h$, k-grid. Two orientations on the cubic substrate (solid, dotted lines) are splitted due to (100)-twinning (light, bold lines).

\section{Time-resolved measurements}

As mentioned earlier the $x$-ray flux directed at a diffraction sample can be increased considerably by using a wider energy band from this spectrum. Good time resolution can be achieved with a PSD detector system and a short sample-to-detector distance. The time resolution is then no longer limited by scanning but instead by the dead time of the detector or the readout frequency of the detector electronics. In the experiments described here a diode chip is a monolithic selfscanning linear diode array which consists of a row of $10^{24}$ silicon photodiodes.

As a test sample to establish the shortest posssible recording times we choose $\mathrm{CaF}_{2}$. With grouped diodes (and as a consequence low angular resolution) we recorded a pattern of the first 4 reflections within 2.5 milliseconds with a ratio of peak/background of about 15:1 for the strongest reflection [6]. 


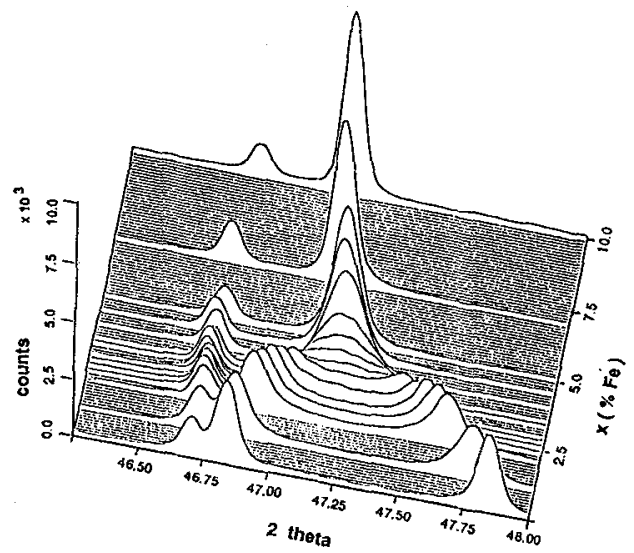

Fig. 7 Synchrotron X-ray powder diffraction patterns of peaks (006), (020) and $(200)$ as a function of Fe content $x$ for samples $\mathrm{YBa}_{2}\left(\mathrm{Cu}_{1-\mathrm{x}} \mathrm{Fe}_{\mathbf{x}}\right)_{3} \mathrm{O}_{7-y}$

As an example for a phase transformation the polymorphic transitions of sodium sulfate $\left(\mathrm{Na}_{2} \mathrm{SO}_{4}\right)$ have been investigated on a time scale of one second for a complete diagram of $20^{\circ}$ in 20. Each diagram consists of 20 single shots. The exposure time for each shot was $50 \mathrm{msec}$ and the single shots were added. The predicted phases V, III and I could be observed by heating the sample with $1.5 \mathrm{~K} / \mathrm{sec}$ (Fig. 12). Cooling the sample with $3 \mathrm{~K} / \mathrm{sec}$ showed the transformation from phase I to phase II to phase III. The observed phase II was only observed on cooling from phase I to phase III. In order to establish the crystal structure of all phases complementary measurements in the high resolution mode were performed. Phase II could thus be indexed with space group Pnam.
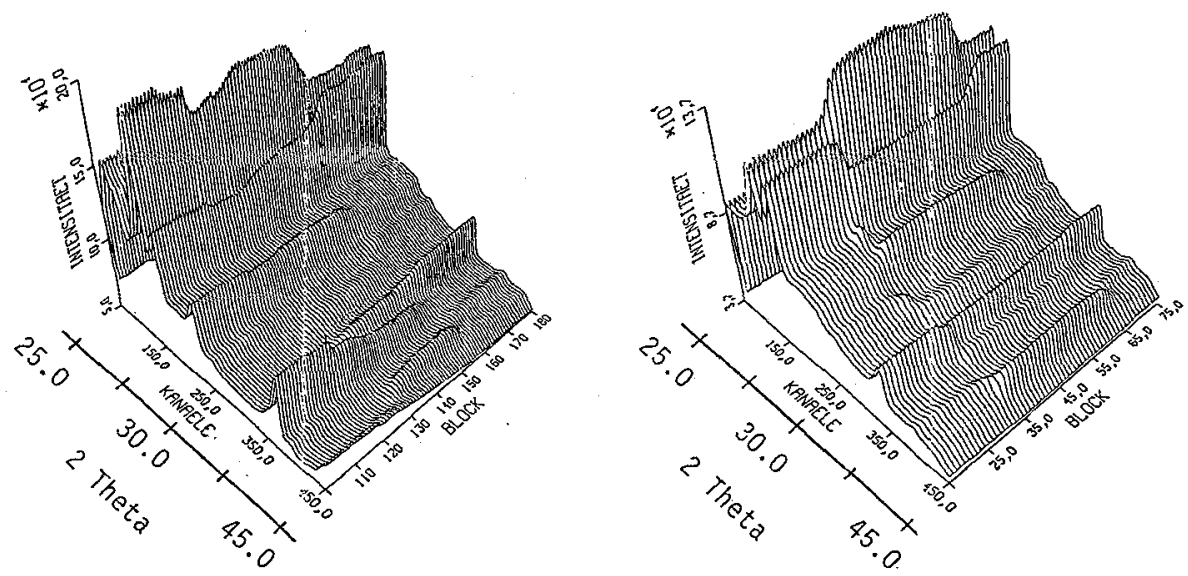

Fig. $8 \mathrm{a} \mathrm{Na}_{2} \mathrm{SO}_{4}$ heating. $\mathrm{Na}_{2}-\mathrm{SO}_{A}$ powder sample (capillary) heated from $30^{\circ} \mathrm{C}$ (trace 100 ) to $320^{\circ} \mathrm{C}$ (trace 180 ) with $1.5^{\circ} \mathrm{C} / \mathrm{s} .1$ pixel=2 diodes, each "Block"= trace is taken within" 1 second.

Fig. 8b $\mathrm{Na}_{2}-\mathrm{SO}_{4}$ powder sample (capillary) colled down from $320^{\circ} \mathrm{C}$ (trace 15) to $170^{\circ} \mathrm{C}$ (trace 65) with $3^{\circ} \mathrm{C} / \mathrm{s}$ and heated up to $185^{\circ} \mathrm{C}$ (trace 75 ) with $1.5^{\circ} \mathrm{C} / \mathrm{s}$. 1 pixel=2 diodes, each "Block"= trace is taken within 1 second. 
These results indicate that the registration of intermediate reaction products and their pathways is feasible as well as the refinement of cell parameters in pattern registered on a timescale of seconds or smaller.

our diffraction experiment are combined with EXAFS and XANES experiments which will provide information on the local environment and on the electronic structure of some of the samples. Furthermore thin films are studied by grazing incidence methods.

\section{Acknowledgement}

Support of this work by the Bundesminister für Forschung and Technology (Bonn, Germany) is gratefully acknowledged.

\section{References}

1. LOECHNER, U, PENNARTZ, P.U., MIEHE, G. and FUESS, H.: z. Kristallogr. 204, (1993), 1

2. RUPPERSBERG, H., DETEMPLE, I. and KRIER, J.: Z. Kristallogr. 195 (1991), -189

3. REN, Y., SCHMAHL, W.W., BRECHT, E., FUESS, H.: Physica C 199 (1992), 414-424

4. SCHMAHL, W.W., PUTNIS, A., SALJE, E., BLUNT, J., ZHANG, D.N., FREEMAN, P., GRAEME-BARBER, A.:

In: proceed. of ICMC 1990, Garmisch-Partenkirchen, 617-622

5. STEINBORN, T., MIEHE, G., WIESNER, J., BRECHT, E., FUESS, H., WIRTH, G., SCHULTE, B., SPECKMANN, M., ADRTAN, H., PETERSEN, K.:

Physica $C$, in press

6. PENNARTZ, P.U., LOECHNER, U., FUESS, H., WROBLEWSKI, T.: J. Apply. Cryst. 25 (1992), 571 